\title{
Understanding the regulation of pituitary progesterone receptor expression and phosphorylation
}

\author{
Ana Gordon ${ }^{*}+$, José C Garrido-Gracia*, Rafaela Aguilar and José E Sánchez-Criado \\ Department of Cell Biology, Physiology and Immunology, University of Córdoba, 14004 Córdoba, Spain \\ Correspondence should be addressed to A Gordon; Email: anagordonbc@gmail.com \\ *(A Gordon and J C Garrido-Gracia contributed equally to this work) \\ ${ }^{+}$A Gordon is now at Infectious Diseases Unit, Hospital Universitario Reina Sofia, Avenida Menédez Pidal, \\ s/n, 14004 Córdoba, Spain
}

\begin{abstract}
Administration of human FSH (hFSH) during the diestrus phase in cyclic rats is followed by a reduction in the preovulatory LH surge. This inhibitory action of FSH involves a decrease in the stimulatory effect of gonadotrope progesterone receptor (PR) activation, in a ligand-dependent (progesterone) and -independent (GNRH) manner. PR activation and action are mandatory for LH surge, and are dependent on the phosphorylation of serine (Ser) residues. Together with this post-translational modification, PR is marked for downregulation by proteasome machinery. These experiments used the western blotting technique to measure pituitary expression of PR-A and PR-B isoforms and phosphorylation levels of Ser294 and Ser400 PR-B in rats bearing i) hFSH treatment or ii) PR downregulation. Treatment with hFSH reduced LH secretion and increased that of estradiol in proestrus afternoon. hFSH injections, without altering PR-A and PR-B content or ratio, caused a reduction in phosphorylation of Ser294 and Ser400 but only when pituitaries were previously challenged with progesterone or GNRH for $2 \mathrm{~h}$. However, while pSer294 levels increased after $2 \mathrm{~h}$ of pituitary incubation with progesterone or GNRH, those of pSer400 were not modified by these in vitro treatments. Finally, progesterone had a biphasic effect: in 2-h incubations increased pituitary PR-A and PR-B content, but after $8 \mathrm{~h}$ caused downregulation and altered PR-A:PR-B ratio. The results provide a potential mechanism through which $\mathrm{LH}$ levels are decreased by $\mathrm{hFSH}$ administration and better understanding of the control of PR expression and phosphorylation in rat pituitaries.
\end{abstract}

Reproduction (2015) 149 615-623

\section{Introduction}

Although the cyclical nature of female reproduction has long been recognized, even now, there are unanswered questions. Crucial and still-unresolved questions are what prompts the start and what causes the end of preovulatory luteinizing hormone $(\mathrm{LH})$ secretion. It has been suggested that gonadotrope progesterone receptor (PR) may play a role in both events. Firstly, administration of human follicle-stimulating hormone (hFSH) to cyclic rats during diestrus attenuates the PR-dependent LH surge in proestrus. Secondly, PR activation by its cognate ligand marks the protein for destruction by the proteasome, causing PR downregulation.

In the rat, gonadotropes are the only pituitary cells expressing this steroid receptor (Turgeon \& Waring 2001), and there is considerable evidence to suggest that expression and activation of PR are obligatory steps for gonadotropin secretion. That PR activation is critically important in the hypothalamic-pituitaryovarian axis is reflected by the observation that the administration of PR antagonists to proestrus or estradiol
$\left(E_{2}\right)$-treated ovariectomized rats, RU486 and ZK299, respectively, blunted the preovulatory secretion of gonadotropin-releasing hormone $(\mathrm{GNRH})$ and consequently that of LH (Sánchez-Criado et al. 1994, Chappell \& Levine 2000). Furthermore, the $\mathrm{E}_{2}$-induced $\mathrm{LH}$ secretion was blocked by the same PR antagonists in rat pituitary incubations (Bellido et al. 1999, SánchezCriado et al. 2005). Interestingly, this receptor functions as a critically important component of the GNRH selfpriming process (Turgeon \& Waring 1994, Chappell et al. 1999) and becomes an absolute requirement for the generation of gonadotropin surges as shown in Pr-knockout mice (Chappell et al. 1999).

$P R$ is a transcriptional factor, expressed as two estrogen-inducible isoforms: PR-A and PR-B (Kastner et al. 1990). PR-B differs from PR-A in 164 amino acids, but this difference is enough to confer different functions to each isoform (with exceptions, PR-A is regarded as the modulator of PR-B; Levine et al. 2001). Phosphorylation, a post-translational modification known to modulate the activity of PR (Denner et al. 1990, Faus \& Haendler 2006), 
takes place exclusively at serine (Ser) residues, which can be divided into basal and induced phosphorylation sites (Takimoto \& Horwitz 1993, Moore et al. 2007). PR is phosphorylated by protein kinases, which in turn are activated by progesterone or in the absence of its cognate ligand (ligand-dependent and -independent activation respectively; Bai et al. 1997). Previous works have shown how GNRH can activate PR in a ligandindependent manner in gonadotropes transfected with reporter plasmids containing progesterone-responsive elements (Turgeon \& Waring 1994). These authors proposed that the cAMP/protein kinase A pathway for GNRH self-priming and progesterone potentiation of GNRH-stimulated LH secretion converge at the PR (Waring \& Turgeon 1992, Turgeon \& Waring 1994). However, although several growth factors and neurotransmitters have been reported to phosphorylate PR (Bai et al. 1997, Pierson-Mullany \& Lange 2004, Daniel et al. 2007), it is not known whether GNRH activation of PR phosphorylates the receptor in pituitary cells.

Administration of $\mathrm{hFSH}$ during the diestrus phase in cyclic rats is followed by a reduction in the preovulatory $\mathrm{LH}$ surge. As ovariectomy reverses the latter effect of hFSH injections, a nonsteroidal ovarian FSH-dependent factor has been proposed (the gonadotropin surgeattenuating factor (GnSAF); Fowler et al. 2003, Messinis 2006, Gordon et al. 2008, 2009a). The mechanism of action through which GnSAF exerts this inhibition may involve an interaction with PR at pituitary level, because it involves a decrease in the stimulatory effect of PR activation in a ligand-dependent (progesterone) and -independent (GNRH) manner (Gordon et al. 2008, 2009b).

On the other hand, PR phosphorylation is linked to proteasome-mediated downregulation (Clemm et al. 2000, Lange et al. 2000). Until recently, phosphorylation of Ser residue 294 was regarded as the signal for proteasome degradation (Lange et al. 2000, Khan et al. 2011). The downregulation phenomenon may be a physiological mechanism for diminishing proestrus LH secretion and avoiding another surge at estrus by eliminating pituitary PR (Turgeon \& Waring 2000). However, while most of the information we have about PR downregulation comes from T47D cells, little is known about ligand-dependent and -independent activation on gonadotrope PR turnover or whether the two isoforms are differently controlled. This study thus sought i) to evaluate whether rats treated with hFSH have a reduction in pituitary $\mathrm{PR}$ protein expression and/or phosphorylation, and ii) to determine whether pituitary PR ligand-dependent (progesterone) and -independent $(G N R H)$ exposure could induce a PR downregulation. For that purpose, an optimized western blot technique was used to investigate the following in rat anterior pituitaries: i) total PR-A and PR-B protein levels, ii) the relationship between the two isoforms
(PR-A:PR-B ratio), and iii) PR-B phosphorylation status at basal and induced sites.

\section{Materials and methods}

\section{Animals and general conditions}

Adult female Wistar rats weighing 190-210 g were housed under a $14 \mathrm{~h}$ light:10 h darkness cycle (lights on at $0500 \mathrm{~h}$ ) at $22 \pm 2{ }^{\circ} \mathrm{C}$ room temperature, with ad libitum access to rat chow and tap water. The rats were included in the experiments after displaying at least three consecutive 4-day estrus cycles. Vaginal smears were taken 6 days/week and the day of vaginal estrus was arbitrarily considered as day 1 . All experimental protocols were approved by the Ethical Committee of the University of Córdoba, and experiments were performed in accordance with rules on laboratory animal care and international law on animal experimentation.

\section{Treatment with hFSH}

Recombinant hFSH (Gonal-f; Serono) was dissolved at a concentration of $50 \mathrm{IU} / \mathrm{ml}$ saline, and $10 \mathrm{IU} \mathrm{hFSH}$ was given s.c. at $1400 \mathrm{~h}$ on day 2 (metestrus) and another dose of $10 \mathrm{IU}$ $\mathrm{hFSH}$ at $0900 \mathrm{~h}$ on day 3 (diestrus). The dose rates and administration protocol for hFSH were determined in the light of previous findings (Gordon et al. 2008). Nonstimulated controls were given $0.2 \mathrm{ml}$ saline.

\section{In vivo experiments}

Firstly, rats were treated in vivo with $\mathrm{hFSH}$ to study its effects on proestrus $\mathrm{E}_{2}, \mathrm{LH}$, and progesterone secretions (controls were injected with saline). At $1600 \mathrm{~h}$ on proestrus, six rats per group (vehicle- and hFSH-injected rats) were lightly etherized and $<0.4 \mathrm{ml}$ blood was obtained by direct jugular venipuncture. Other blood samples were obtained at $1800 \mathrm{~h}$ (the high level of the LH surge in this colony; Sánchez-Criado et al. 1990) and at $2400 \mathrm{~h}$ on proestrus. Blood was allowed to clot, centrifuged at $4{ }^{\circ} \mathrm{C}$, and the serum stored at $-20{ }^{\circ} \mathrm{C}$ until quantified for $\mathrm{E}_{2}$, $\mathrm{LH}$, and progesterone by specific RIAs.

\section{RIA of $L H, E_{2}$, and progesterone}

Serum LH concentrations were measured in duplicate by RIA using a double antibody method with a kit supplied by the National Institutes of Health (NIH; Bethesda, MD, USA) and a previously described micro-assay method (Sánchez-Criado et al. 1990). Rat LH-I-10 was labeled with ${ }^{125}$ I using the chloramine $\mathrm{T}$ method. All samples were assayed in the same assay; the intra-assay coefficient of variation (CV) was $8 \%$, and assay sensitivity was $3.75 \mathrm{pg} /$ tube. Results are expressed as $\mathrm{ng} / \mathrm{ml}$ of the RP LH-rat-RP-3. Serum $\mathrm{E}_{2}$ and progesterone concentrations were determined in duplicate using commercially obtained kits (Diagnosis Products Corporation, Los Angeles, CA, USA). The sensitivity of the assays was 1 and $10 \mathrm{pg} /$ tube and the intra-assay $\mathrm{CV}$ were 7 and $6 \%$ respectively. $\mathrm{E}_{2}$ and progesterone concentrations are expressed as $\mathrm{pg} / \mathrm{ml}$ and $\mathrm{ng} / \mathrm{ml}$ serum respectively. 


\section{In vitro experiments}

\section{General pituitary incubation protocol}

Incubation of pituitaries was carried out, with minor modifications, as described previously (Gordon et al. 2008). Briefly, pituitaries were incubated at $37^{\circ} \mathrm{C}$ with constant shaking (60 cycles/min) in an atmosphere of $95 \% \mathrm{O}_{2}$ and $5 \%$ $\mathrm{CO}_{2}$. Each incubation vial contained $250 \mu \mathrm{l}$ DMEM without L-glutamine and phenol red and containing glucose $(4.5 \mathrm{~g} / \mathrm{l})$, $10^{-8} \mathrm{M} \mathrm{E}_{2}$ (Sigma Chemical Co.) and BSA (0.1\% w/v, pH 7.4). Pituitaries were stabilized for $1 \mathrm{~h}$ of pre-incubation in the latter medium but without test substances (progesterone or GNRH). Before carrying out experiments 'Effects of hFSH on pituitary PR expression and phosphorylation' section and 'Effects of long-term exposure to progesterone or GNRH on pituitary PR expression and phosphorylation' section, an incubation protocol was optimized to study phosphorylated PR levels: pituitaries from proestrus rats were incubated with $E_{2}$ and progesterone for 30,60 , or 120 min to determine the optimal timing of PR phosphorylation. As a result, $2 \mathrm{~h}$ was taken to be the most favorable incubation period for PR activation (data not shown) and was used thereafter to compare with the effects of hFSH (experiment 'Effects of hFSH on pituitary PR expression and phosphorylation') or long-term incubation with progesterone or GNRH (experiment 'Effects of long-term exposure to progesterone or GNRH on pituitary PR expression and phosphorylation'). This treatment was supported by previous research (Clemm et al. 2000, Pierson-Mullany \& Lange 2004).

\section{Effects of hFSH on pituitary PR expression and phosphorylation}

To determine relative levels of PR protein and phosphorylated $\mathrm{PR}-\mathrm{B}$ isoform, in vivo $\mathrm{hFSH}$ - and saline-treated rats $(n=15)$ were decapitated at $0900 \mathrm{~h}$ on day 4 ; their pituitary glands were removed, separated from the neural lobe, and incubated for $2 \mathrm{~h}$ with $10^{-8} \mathrm{M} \mathrm{E} \mathrm{E}_{2}$ and i) $10^{-6} \mathrm{M}$ progesterone (ligand-dependent activator of PR), ii) $10^{-7} \mathrm{M}$ GNRH (ligand-independent activator of PR), or iii) medium alone ( $n=5$ /group) (for more details, see 'General pituitary incubation protocol' section) (Gordon et al. 2009b). At the end of the incubation period, the pituitaries were collected, snapfrozen, and stored at $-80{ }^{\circ} \mathrm{C}$ until use. Tissues samples were homogenized in RIPA buffer $(150 \mathrm{mM} \mathrm{NaCl}, 1 \%$ Triton X-100, $0.5 \%$ sodium deoxicholate, $0.1 \%$ SDS and $50 \mathrm{mM}$ Tris- $\mathrm{HCl}$, $\mathrm{pH}$ 8.0) with a protease and phosphatase inhibitor cocktail (Thermo Fisher Scientific, Inc., Waltham, MA, USA). Proteins were obtained by centrifugation for $15 \mathrm{~min}$ at $17949 \mathrm{~g}$ at $4{ }^{\circ} \mathrm{C}$, and supernatant was quantified by the Bradford method (BioRad). Equal amount of proteins $(100 \mu \mathrm{g} /$ lane $)$ was separated using SDS-PAGE (7.5\%) with a Mini-Protean System (Bio-Rad) and transferred over $1 \mathrm{~h}$ to Immobilon-P transfer membranes (Millipore, Bedford, MA, USA). The membranes were blocked for $2 \mathrm{~h}$ in $5 \%$ nonfat dry milk diluted in $0.05 \%$ Tween-20 Tris-buffered saline and incubated overnight with the primary antibodies: rabbit polyclonal antibody against PR (PR C-20: sc-539; Santa Cruz Biotechnology; diluted 1:500), which recognizes both $\mathrm{PR}$ isoforms (PR-A and PR-B) in rats; the commercial mouse monoclonal phospho-PR (pSer294) antibody clone 608, raised against the immunogen P(288)MAPGRS(p)PLATTV(300) located in the N-terminal domain (Affinity BioReagents, Golden, CO, USA; diluted 1:5000); and the commercial rabbit polyclonal phospho-PR (pSer400) antibody, raised against the immunogen synthetic phosphopeptide derived from human PR around the phosphorylation site of Ser400 (A-R-SP-P-R) (Abcam, London, UK; diluted 1:5000). The antibodies pSer294 and pSer400 were selected to measure hormone-induced and basal phosphorylation levels of PR-B respectively. Finally, a rabbit $M A B$ against $\alpha$-tubulin (Abcam; diluted 1:10 000) was used as a loading control. After incubation with primary antibodies, membranes were washed and incubated for $1 \mathrm{~h}$ with HRP-coupled secondary antibody (Jackson Immunoresearch Laboratories, Inc., West Grove, PA, USA; diluted 1:5000). Immunoreactive bands were detected using an ECL system (Immobilon Western, Millipore, Billerica, MA, USA). Quantification of the intensity of western blot signals was carried out using a Java-based image processing and analysis program developed by the NIH (ImageJ) and the values for the specific signal (PR-A, PR-B, pSer294 RP-B, and pSer400 RP-B) were normalized to loading control.

\section{Effects of long-term exposure to progesterone or GNRH on pituitary PR expression and phosphorylation}

Recent in vivo research has suggested that the proestrus progesterone surge lasts $\sim 8 \mathrm{~h}$ in saline-injected rats (Fig. 1); this was therefore the interval used to study PR downregulation, in a treatment schedule supported by other authors (Turgeon et al. 1999, Clemm et al. 2000, Turgeon \& Waring 2000). To determine the effect of progesterone and GNRH on phosphorylation and downregulation of $\mathrm{PR}$, pituitaries from 30 proestrus rats were incubated for $2 \mathrm{~h}$ (short-term group) or $8 \mathrm{~h}$ (long-term group) with $10^{-8} \mathrm{M} \mathrm{E}_{2}$ and i) $10^{-6} \mathrm{M}$ progesterone, ii) $10^{-7} \mathrm{M} \mathrm{GNRH}$, or iii) medium alone $(n=5 /$ group) (for more details, see 'General pituitary incubation protocol' section). Relative levels of PR protein and phosphorylated PR-B isoform were evaluated using the western blot technique and antibodies, as previously detailed in 'Effects of hFSH on pituitary PR expression and phosphorylation' section.

\section{Statistical analyses}

Statistical analysis was performed by two-way ANOVA to test for significant differences among groups. When significant differences existed, ANOVA was followed by the StudentNewman-Keul's multiple range test to compare means. Significance was considered at the 0.05 level. Linear regression was used to evaluate the relationship between PR-A and PR-B protein levels obtained in PR downregulation experiments, as well as between PR-B and phosphorylated residues (pSer294 and pSer400). Linear regression was performed considering the significance of the regression parameters and coefficient of determination $\left(R^{2}\right)$. Data from all experiments were analyzed by Statistix 9 (Analytical Software, Tallahassee, FL, USA). 

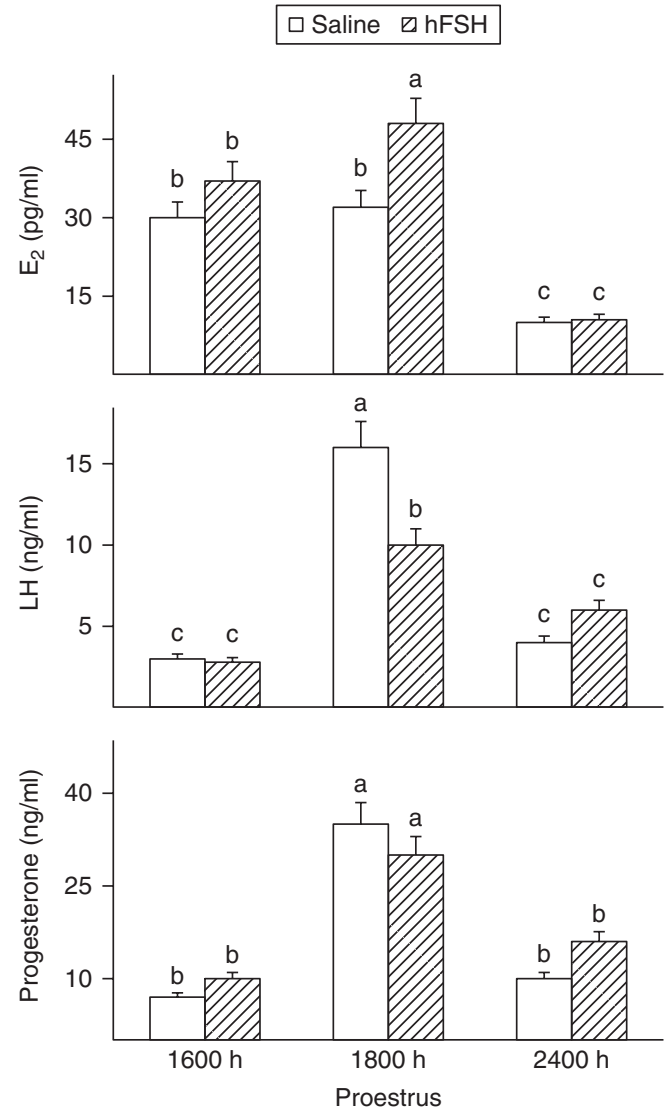

Figure 1 Effects of $h F S H$ treatment on serum estradiol $17 \beta\left(E_{2}\right), \mathrm{LH}$, and progesterone levels at 1600,1800 , and $2400 \mathrm{~h}$ on the day of proestrus. Adult female rats were injected with $0.2 \mathrm{ml}$ saline or $10 \mathrm{IU} \mathrm{hFSH}$ during the diestrus phase $(1400 \mathrm{~h}$ in metestrus and $0900 \mathrm{~h}$ in diestrus). Values are means \pm S.E.M. of six rats per group. Differences among groups with different letters are statistically significant $(P<0.05$; ANOVA followed by Student-Newman-Keul's multiple range test).

\section{Results}

Serum $E_{2}, L H$, and progesterone levels during proestrus afternoon in rats injected with $\mathrm{hFSH}$

Serum LH and progesterone concentrations were at baseline levels at $1600 \mathrm{~h}$, peaked $2 \mathrm{~h}$ later $(1800 \mathrm{~h})$, and returned to baseline at $2400 \mathrm{~h}$, both in saline- and $\mathrm{hFSH}$ injected rats (Fig. 1). In contrast, serum $\mathrm{E}_{2}$ levels were high at 1600 and $1800 \mathrm{~h}$, and returned to baseline values at $2400 \mathrm{~h}$. While $\mathrm{hFSH}$ treatment increased serum $\mathrm{E}_{2}$ concentrations at $1800 \mathrm{~h}$, it attenuated $\mathrm{LH}$ concentrations at the high of the LH peak (Fig. 1).

\section{Effects of hFSH treatment on PR-A and PR-B isoforms and PR-A:PR-B ratio in pituitaries from proestrus rats after incubation with progesterone, GNRH, or DMEM for $2 h$}

Pituitaries incubated for $2 \mathrm{~h}$ with progesterone showed increased signals of both PR isoforms when compared with pituitaries incubated with DMEM $(P<0.05$; Fig. 2, upper panel). The latter effect was not influenced by in vivo treatment (saline or hFSH). Medium PR signal levels were found in GNRH groups, but differences with respect to control or progesterone groups were not statistically significant (Fig. 2, upper panel). No differences were observed in the PR-A:PR-B ratio between rats treated with saline or $\mathrm{hFSH}$ and their respective incubation sub-groups (Fig. 2, lower panel).
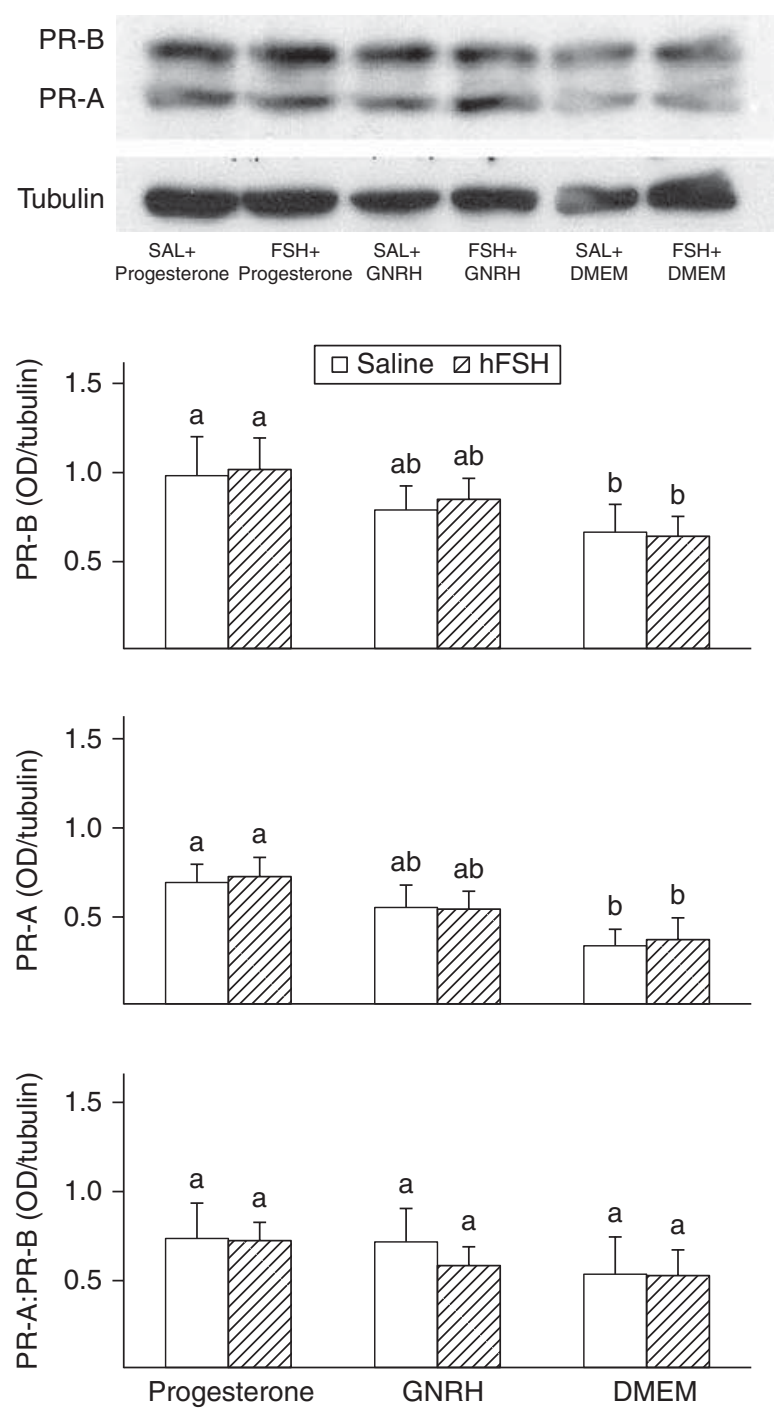

Figure 2 Effects of hFSH treatment on PR isoform protein levels and PR-A:PR-B ratio. Adult female rats were injected with saline or hFSH during the diestrus phase and killed on proestrus morning. After $1 \mathrm{~h}$ of pre-incubation with the medium containing only $10^{-8} \mathrm{ME}_{2}$, pituitaries were incubated for $2 \mathrm{~h}$ with $\mathrm{E}_{2}$ and i) $10^{-6} \mathrm{M}$ progesterone, ii) $10^{-7} \mathrm{M}$ GNRH, or iii) medium. The upper panel is a representative western blot of PR-A, PR-B, and tubulin. Lower panels are densitometric analyses of PR-A, PR-B, and the PR-A:PR-B ratio. Values are means \pm S.E.M. of five rats per group. Differences among groups with different letters are statistically significant $(P<0.05$; ANOVA followed by StudentNewman-Keul's multiple range test). 
Effects of hFSH treatment on phosphorylated Ser294 and Ser400 residues of $P R-B$ in pituitaries from proestrus rats after incubation with progesterone, GNRH, or DMEM for $2 h$

In saline groups, incubation with progesterone or GNRH prompted higher levels of Ser294 phosphorylation than DMEM $(P<0.05$; Fig. 3, upper panel). Conversely, Ser400 phosphorylation levels in saline groups showed no change when pituitaries were incubated either with progesterone or GNRH (Fig. 3, lower panel). Pituitaries from hFSH-treated rats showed significantly decreased rates of phosphorylation in both Ser294 and Ser400 after incubation for $2 \mathrm{~h}$ with progesterone or GNRH $(P<0.05$;
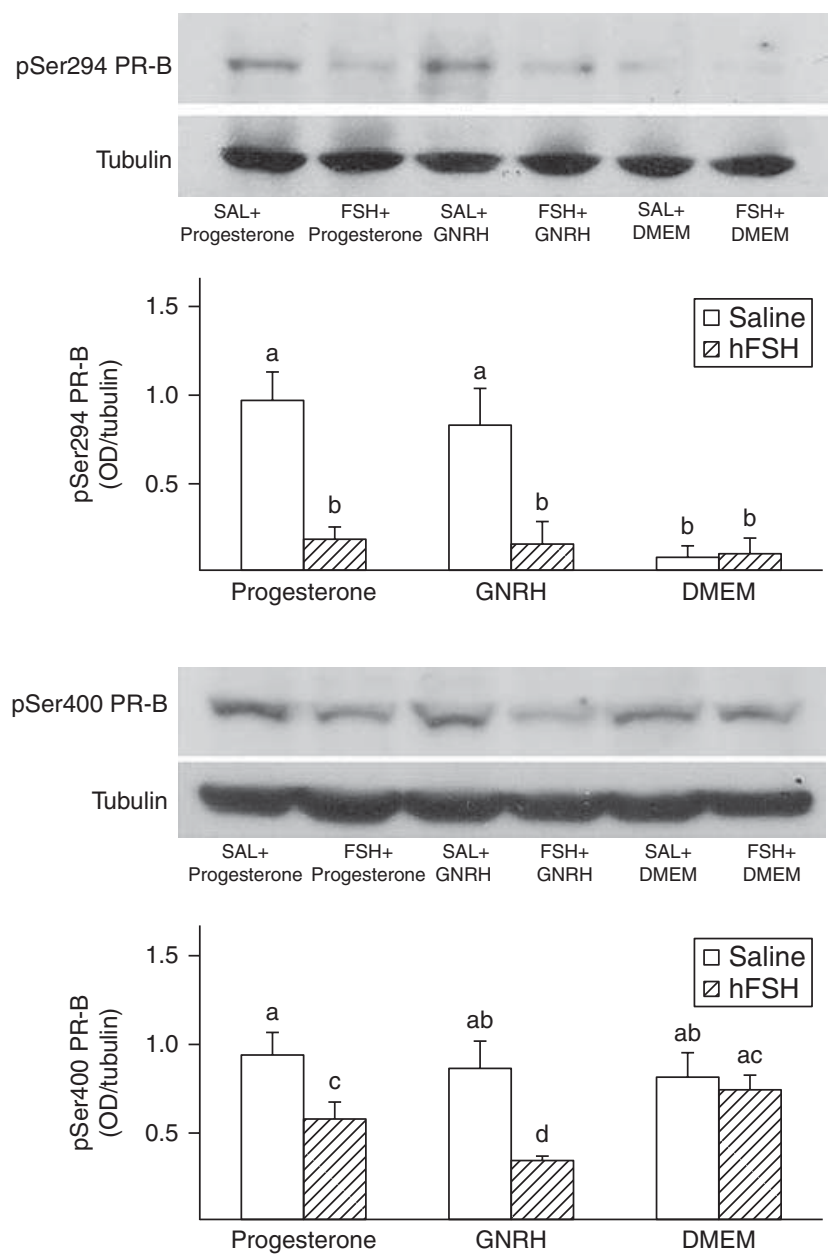

Figure 3 Effects of hFSH treatment on phospho-Ser294 and phosphoSer400 PR-B protein levels. Adult female rats were injected with saline or $\mathrm{hFSH}$ during the diestrus phase and killed on proestrus morning. After $1 \mathrm{~h}$ of pre-incubation with medium containing only $10^{-8} \mathrm{M} \mathrm{E}_{2}$, pituitaries were incubated for $2 \mathrm{~h}$ with $\mathrm{E}_{2}$ and i) $10^{-6} \mathrm{M}$ progesterone, ii) $10^{-7} \mathrm{M} \mathrm{GNRH}$, or iii) medium. Upper panels are representative western blots of phospho-Ser294, phospho-Ser400, and tubulin. Lower panels are densitometric analyses of phospho-Ser294 and phosphoSer400 PR-B. Values are means \pm S.E.M. of five rats per group. Differences among groups with different letters are statistically significant $(P<0.05$; ANOVA followed by Student-Newman-Keuls multiple range test).
Fig. 3, upper and lower panels). However, the dephosphorylation effect of hFSH on pSer400 varied when ligand-dependent and -independent activation were compared, being more intense in the latter $(P<0.05$; Fig. 3, lower panel). Interestingly, no changes were observed in pSer400 levels between saline- and hFSHinjected rats when pituitaries were incubated with DMEM (Fig. 3, lower panel).

\section{Effects of incubation for 2 or $8 \mathrm{~h}$ with progesterone, GNRH, or DMEM on PR-A and PR-B isoforms and $P R-A: P R-B$ ratio in pituitaries from proestrus rats}

As in the $\mathrm{hFSH}$ experiments, pituitaries exposed for $2 \mathrm{~h}$ with progesterone, but not with GNRH, showed increased signals of both PR isoforms levels, in comparison with pituitaries incubated for $2 \mathrm{~h}$ with DMEM ( $P<0.05$; Fig. 4, upper panel). PR-A and PR-B bands decreased significantly after $8 \mathrm{~h}$ of incubation with progesterone or GNRH when compared with their respective 2 -h groups $(P<0.05)$, but only in the case of PR-B protein levels were lower than controls $(P<0.05)$ (Fig. 4, upper panel). Regardless of the incubation time, no differences in PR-A:PR-B ratio were found between DMEM and GNRH groups. However, pituitaries exposed for $8 \mathrm{~h}$ with progesterone displayed an increased PR-A:PR-B ratio due to greater destruction of the PR-B isoform $(P<0.05$; Fig. 4, lower panel).

\section{PR-B phosphorylation levels at Ser294 and Ser400 residues in pituitaries from proestrus rats incubated for 2 or $8 \mathrm{~h}$ with progesterone, GNRH, or DMEM}

While no differences were found between 2 and $8 \mathrm{~h}$ DMEM groups at either pSer294 or pSer400 residue, striking differences appeared in those pituitaries incubated with progesterone or GNRH (Fig. 5). When pSer294 levels were measured, the groups of pituitaries incubated for $2 \mathrm{~h}$ with progesterone or GNRH exhibited a similar rise in phosphorylation of $\mathrm{PR}-\mathrm{B}(P<0.05$; Fig. 5, upper panel). In contrast, no differences were found in pSer400 levels among groups incubated with any test substances for $2 \mathrm{~h}$ (Fig. 5, lower panel). Regardless of the phosphorylated Ser residue studied for PR-B, the incubation of pituitaries for $8 \mathrm{~h}$ with progesterone or GNRH diminished signal levels when compared with their respective short-term incubation groups $(P<0.05$; Fig. 5, upper and lower panels).

\section{General correlation between $P R-A$ and $P R-B$ protein expression in rat pituitaries}

On the basis of data obtained in the PR downregulation experiment, a positive linear correlation was observed between protein levels of the two isoforms (PR-B $=$ $0.2128+1.158 \times$ PR-A; $\quad R^{2}=0.4816 ; \quad P<0.0001$ ) Likewise, total PR-B protein levels displayed a linear 

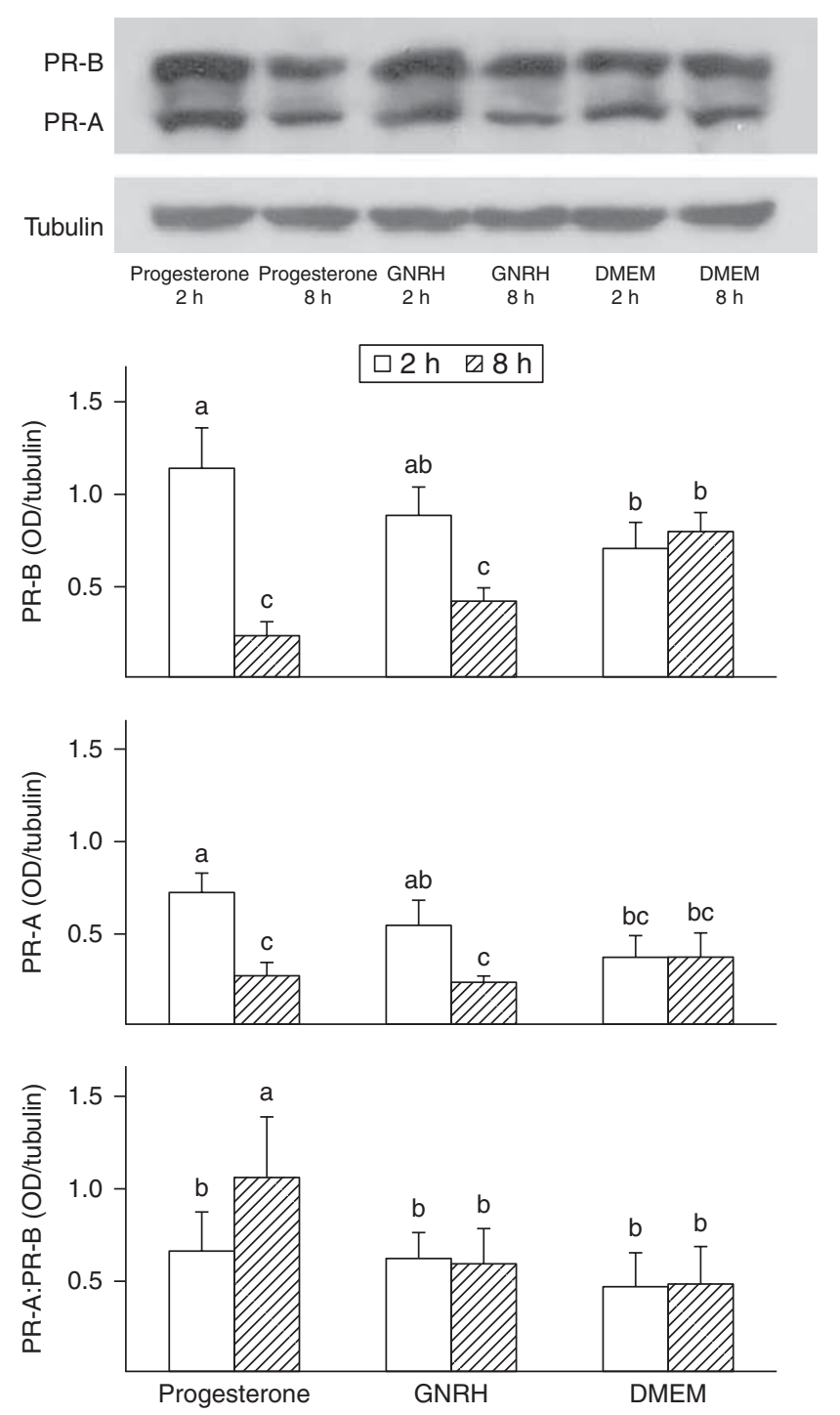

Figure 4 Effects of short- and long-term incubation on PR isoform protein levels and the PR-A:PR-B ratio. Cycling adult female rats were killed on proestrus morning. After $1 \mathrm{~h}$ of pre-incubation with the medium containing only $10^{-8} \mathrm{ME}_{2}$, pituitaries were incubated for 2 or $8 \mathrm{~h}$ with $\mathrm{E}_{2}$ and i) $10^{-6} \mathrm{M}$ progesterone, ii) $10^{-7} \mathrm{M} \mathrm{GNRH}$, or iii) medium. The upper panel is a representative western blot of PR-A, PR-B, and tubulin. Lower panels are densitometric analyses of PR-A, $P R-B$, and the PR-A:PR-B ratio. Values are means \pm s.E.M. of five rats per group. Differences among groups with different letters are statistically significant $(P<0.05$; ANOVA followed by Student-Newman-Keul's multiple range test).

correlation with those of pSer294 (PR-B $=0.05205+$ $0.4879 \times$ pSer294; $\left.R^{2}=0.3207 ; P<0.001\right)$ and pSer400 $\left(\mathrm{PR}-\mathrm{B}=0.8265 \times\right.$ pSer400; $\left.R^{2}=0.8783 ; P<0.0001\right)$. Conversely, no correlation was found between the two Ser residues.

\section{Discussion}

The results reported in this study show that administration of $\mathrm{hFSH}$ reduces preovulatory $\mathrm{LH}$ secretion in proestrus rats, and that this action might be mediated by lowering ligand-dependent and -independent phosphorylation of PR-B without affecting pituitary protein levels of both $\mathrm{PR}$ isoforms. Moreover, whereas incubation of proestrus pituitaries with progesterone or GNRH for $2 \mathrm{~h}$ increases in phosphorylated Ser294 levels, long-term (8 h) incubation with both hormones causes ligand-dependent or independent PR downregulation and, as a consequence, a reduction in phosphorylated PR-B isoform. As far as the authors are aware, this is the first report on the liganddependent and -independent phosphorylation of Ser294
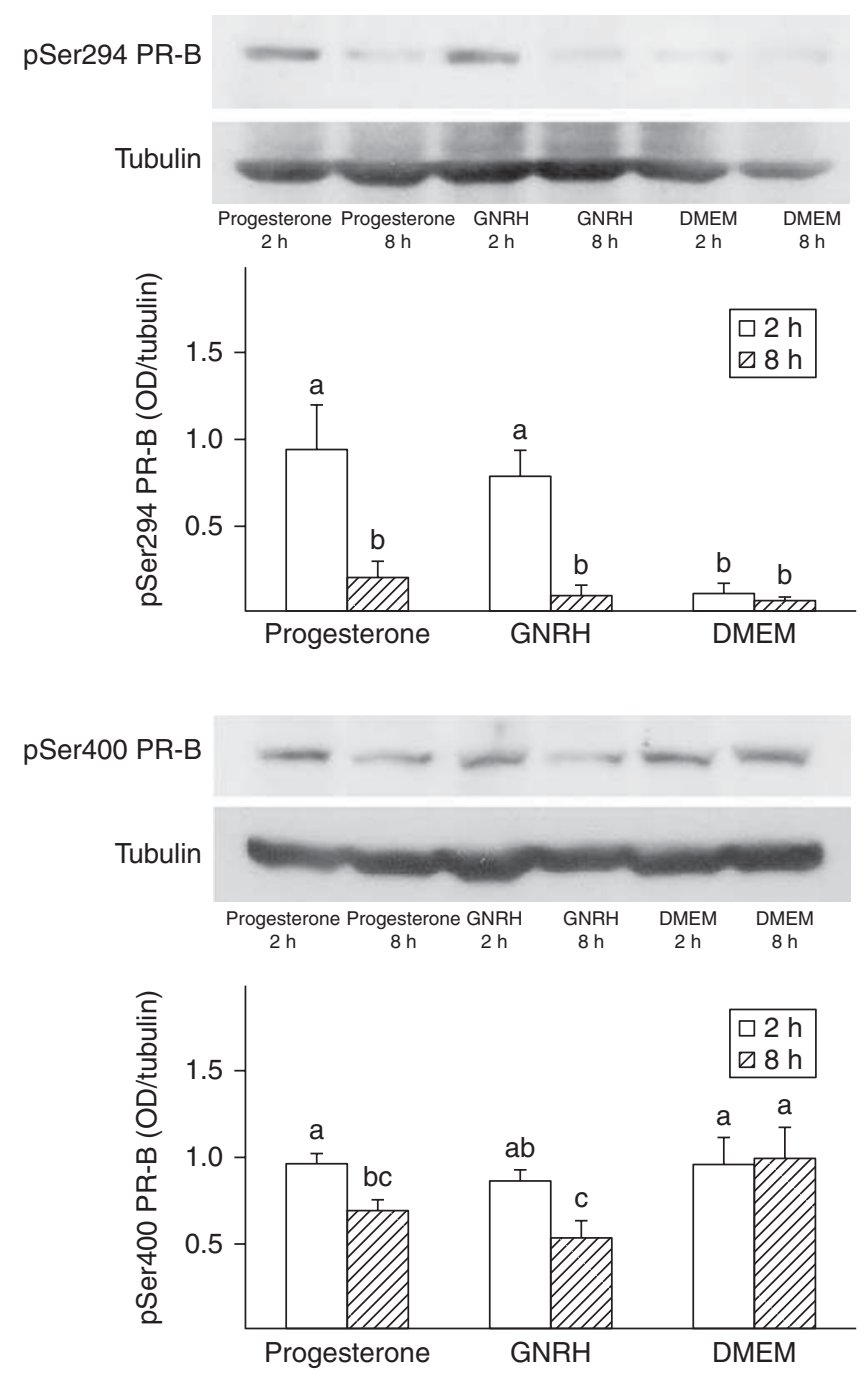

Figure 5 Effects of short- and long-term incubation on phospho-Ser294 and phospho-Ser400 PR-B protein levels. Cycling adult female rats were killed on proestrus morning. After $1 \mathrm{~h}$ of pre-incubation with the medium containing only $10^{-8} \mathrm{ME}_{2}$, pituitaries were incubated for 2 or $8 \mathrm{~h}$ with $\mathrm{E}_{2}$ and i) $10^{-6} \mathrm{M}$ progesterone, ii) $10^{-7} \mathrm{M} \mathrm{GNRH}$, or iii) medium. Upper panels are representative western blots of phosphoSer294, phospho-Ser400, and tubulin. Lower panels are densitometric analyses of phospho-Ser294 and phospho-Ser400 PR-B. Values are means \pm S.E.M. of five rats per group. Differences among groups with different letters are statistically significant $(P<0.05$; ANOVA followed by Student-Newman-Keul's multiple range test). 
and Ser400 in PR-B from rat gonadotropes using the western blot technique. The quantification of total and phosphorylated forms of PR-B has allowed us to delve into the mechanisms of action of GnSAF and examine the evidence of PR downregulation in pituitaries from proestrus rats.

It is widely accepted that administration of $\mathrm{hFSH}$ to diestrus rats prompts a reduction in $\mathrm{LH}$ secretion on proestrus afternoon (Busbridge et al. 1988, Gordon et al. $2008,2009 b)$. Depending on previous in vitro results by our group (Gordon et al. 2009a) and because GnSAF decreases all PR-dependent parameters of $\mathrm{LH}$ secretion, it may be postulated that this action is exerted through a modification of PR expression and/or action (GarridoGracia et al. 2007). Nevertheless, the effect of hFSH treatment on $\mathrm{LH}$ preovulatory secretion does not appear to be due either to an increase in the inhibitory isoform (PR-A) or to a decrease in PR-B. Moreover, in this study, no alterations in the PR-A:PR-B ratio are observed between saline- and $\mathrm{hFSH}$-injected rats (Fig. 2, upper and lower panels). Overall, these findings would suggest that GnSAF inhibit LH preovulatory secretion by a mechanism other than alteration in gonadotrope PR protein levels.

PR is a phosphoprotein that contains several phosphorylation sites, Ser residues, which are susceptible to constitutive or ligand-induced modification (Lange 2008). In several reports, this type of post-translational modification has been shown to alter receptor transcriptional activation, stability, localization, and protein complex formation (Lange 2008, Daniel et al. 2009, Knutson et al. 2012). Previous findings in hFSH-treated rats showed that calyculin (a potent inhibitor of intracellular phosphatases; Condrescu et al. 1999) reduced the inhibitory action of $\mathrm{hFSH}$ on $\mathrm{LH}$ secretion in a dose-dependent manner (Gordon et al. 2009b). Consistent with the above, this study found that, while PR protein levels did not change when rats were injected with hFSH, both Ser residues (Ser294 and Ser400) were dephosphorylated (Fig. 3, upper and lower panels). Taken in conjunction, these results suggest that the inhibitory effect of GnSAF on preovulatory LH secretion may involve an imbalance between the activities of protein kinases and phosphatases, resulting in a dephosphorylation of rat pituitary PR. However, given that we administrated hFSH in vivo, it is likely that PR dephosphorylation occurs in other brain areas such as hipotalamic regions. In fact, transcription and activation of $\mathrm{PR}$ in the hypothalamus are obligatory events in the induction of the GNRH and LH surges in $\mathrm{E}_{2}$-primed, ovariectomized rats (Chappell \& Levine 2000). As kisspeptin neurons of the anteroventral periventricular nucleus expressed $\mathrm{PR}$ and project directly to GNRH neurons (Clarkson \& Herbison 2006, Herbison 2007), GnSAF could increase its effects on LH secretion by inhibiting the activation of these PR by neuroprogesterone.
One striking finding of this experiments was that Ser400 did not display increased phosphorylation after progesterone or GNRH challenge (Figs 3 and 5, lower panels). We are unable to explain why in T47D cells this Ser residue presented higher phosphorylation levels when challenged with the PR agonist R5020 (PiersonMullany \& Lange 2004), while progesterone did not do so in rat gonadotropes (present results). In addition to the higher potency of R5020, it is possible that PR from tumoral cells does not behave in the same way as gonadotrope PR to progesterone in intact rats. In fact, no difference was found in PR pSer400 levels as a function of different incubation times with progesterone $(30,60$, or 120 min; results not shown).

Protein and mRNA of PR have been shown to vary in different rat brain regions and under distinct hormonal conditions, such as during the estrus cycle or after sexual maturity (Camacho-Arroyo et al. 1998, Guerra-Araiza et al. 2001). In fact, there are brain areas where PR is induced by $E_{2}$, independent of $E_{2}$, downregulated by progesterone or not modified by progesterone (Camacho-Arroyo et al. 1998, Guerra-Araiza et al. 2003). However, although most of the studies about the regulation of PR expression in the brain have been carried out after long-term exposures with progesterone (Camacho-Arroyo et al. 1998, Guerra-Araiza et al. 2003, Attardi et al. 2007), we have used short- and long-term pituitary incubations to evaluate PR protein phosphorylation and turnover. Interestingly, present results showed that gonadotropes challenged with progesterone for $2 \mathrm{~h}$ displayed a greater PR-A and PR-B immunoreactivity, which implies a greater protein expression (Figs 2 and 4). It is likely that short-term exposure to progesterone could stimulate translation of already present $P R$ mRNA by activating membrane PRs instead of, destroying it as has been proposed (Turgeon et al. 1999). On the other hand, after $8 \mathrm{~h}$ of exposure to progesterone or GNRH, pituitaries suffered PR downregulation (Fig. 4), which even prompted a change in the PR-A:PR-B ratio in the case of progesterone (Fig. 4, lower panel). The PR-A: $\mathrm{PR}-\mathrm{B}$ expression ratio is a key factor in tissue responsiveness to several stimuli; many reports have made an intensive study of this ratio and its link with cancer (Shyamala et al. 1998, Mote et al. 2002, Khan et al. 2011). PR-B protein degrades faster than PR-A (Khan et al. 2011), as also observed when pituitaries were incubated with progesterone, changing the PR-A:PR-B ratio. GNRH-induced PR phosphorylation and activation, through second messengers, provoked ligand-independent downregulation but, in contrast to progesterone, GNRH did not modify the PR-A:PR-B ratio (Fig. 4, lower panel). One possible explanation is that the mechanisms controlling PR isoform degradation/stability change as a function of the external stimulus (Khan et al. 2011). Like other researchers, we would suggest that while short-term administration of progesterone or GNRH activates PR, long-term exposure causes PR 
downregulation (Turgeon et al. 1999, Turgeon \& Waring 2000, present results). However, pituitaries were continuously incubated with GNRH, which implies physiological differences with GNRH pulses in proestrus afternoon. In this setting, the detailed mechanism underlying the specific PR isoform turnover requires further investigation.

In the context of the mechanisms controlling $\mathrm{LH}$ preovulatory secretion, both groups of experiments tempted us to provide a possible hypothesis regarding the optimal timing of the LH surge: firstly, given that GnSAF is produced during diestrus (Tébar et al. 1998), this factor might inhibit phosphorylation of gonadotrope PR already present at this period, which would avoid a premature LH surge. Secondly, the LH surge-dependent progesterone rise during proestrus afternoon would phosphorylate PR-B, marking it for PR downregulation through degradation by the $26 \mathrm{~S}$ proteosome (Lange et al. 2000), which would impede another surge of LH during estrus.

\section{Declaration of interest}

The authors declare that there is no conflict of interest that could be perceived as prejudicing the impartiality of the research reported.

\section{Funding}

This study was supported by grants BFU2008-0048 from DGICYT and P07-CVI-2559 from CICE-Junta de Andalucía (Spain).

\section{Acknowledgements}

The authors are grateful to the National Hormone and Pituitary Program (Baltimore, MD, USA) for the LH RIA kit.

\section{References}

Attardi B, Scott R, Pfaff D \& Fink G 2007 Facilitation or inhibition of the oestradiol-induced gonadotrophin surge in the immature female rat by progesterone: effects on pituitary responsiveness to gonadotrophinreleasing hormone (GNRH), GNRH self-priming and pituitary mRNAs for the progesterone receptor A and B isoforms. Journal of Neuroendocrinology 19 988-1000. (doi:10.1111/j.1365-2826.2007.01613.x)

Bai W, Rowan BG, Allgood VE, O'Malley BW \& Weigel NL 1997 Differential phosphorylation of chicken progesterone receptor in hormone-dependent and ligand-independent activation. Journal of Biological Chemistry 272 10457-10463. (doi:10.1074/jbc.272.16. 10457)

Bellido C, Gonzalez D, Aguilar R \& Sánchez-Criado JE 1999 Antiprogestins RU486 and ZK299 suppress basal and LHRH-stimulated FSH and LH secretion at pituitary level in the rat in an oestrous cycle stage-dependent manner. Journal of Endocrinology 163 79-85. (doi:10.1677/joe.0. 1630079)

Busbridge NJ, Buckley DM, Cornish M \& Whitehead SA 1988 Effects of ovarian hyperstimulation and isolated preovulatory follicles on $\mathrm{LH}$ responses to $\mathrm{GnRH}$ in rats. Journal of Reproduction and Fertility $\mathbf{8 2}$ 329-336. (doi:10.1530/jrf.0.0820329)
Camacho-Arroyo I, Guerra-Araiza C \& Cerbón MA 1998 Progesterone receptor isoforms are differentially regulated by sex steroids in the rat forebrain. Neuroreport 9 3993-3996. (doi:10.1097/00001756-199812 210-00001)

Chappell PE \& Levine JE 2000 Stimulation of gonadotropin-releasing hormone surges by estrogen. I. Role of hypothalamic progesterone receptors. Endocrinology 141 1477-1485. (doi:10.1210/endo.141.4. 7428)

Chappell PE, Schneider JS, Kim P, Xu M, Lydon JP, O'Malley BW \& Levine JE 1999 Absence of gonadotropin surges and gonadotropin-releasing hormone self-priming in ovariectomized $(\mathrm{OVX})$, estrogen $\left(\mathrm{E}_{2}\right)$-treated, progesterone receptor knockout (PRKO) mice. Endocrinology 140 3653-3658.

Clarkson J \& Herbison AE 2006 Postnatal development of kisspeptin neurons in mouse hypothalamus; sexual dimorphism and projections to gonadotropin-releasing hormone neurons. Endocrinology 147 5817-5825. (doi:10.1210/en.2006-0787)

Clemm DL, Sherman L, Booyaratanakornkit V, Schrader WT, Weigel NL \& Edwards DP 2000 Differential hormone-dependent phosphorylation of progesterone receptor $\mathrm{A}$ and $\mathrm{B}$ forms revealed by a phosphoserine sitespecific monoclonal antibody. Molecular Endocrinology 14 52-65. (doi:10.1210/mend.14.1.0413)

Condrescu M, Hantash BM, Fang Y \& Reeves JP 1999 Mode-specific inhibition of sodium calcium exchange during protein phosphatase blockade. Journal of Biological Chemistry 274 33279-33286. (doi:10. 1074/jbc.274.47.33279)

Daniel AR, Faivre EJ \& Lange CA 2007 Phosphorylation-dependent antagonism of sumoylation derepresses progesterone receptor action in breast cancer cells. Molecular Endocrinology 21 2890-2906. (doi:10. 1210/me.2007-0248)

Daniel AR, Knutson TP \& Lange CA 2009 Signaling inputs to progesterone receptor gene regulation and promoter selectivity. Molecular and Cellular Endocrinology 308 47-52. (doi:10.1016/j.mce.2009.01.004)

Denner LA, Weigel NL, Maxwell BL, Schrader WT \& O'Malley BW 1990 Regulation of progesterone receptor-mediated transcription by phosphorylation. Science 250 1740-1743. (doi:10.1126/science.2176746)

Faus H \& Haendler B 2006 Post-translational modifications of steroid receptors. Biomedicine \& Pharmacotherapy 60 520-528. (doi:10.1016/j. biopha.2006.07.082)

Fowler PA, Sorsa-Leslie T, Harris W \& Mason HD 2003 Ovarian gonadotrophin surge-attenuating factor (GnSAF): where are we after 20 years of research? Reproduction 126 689-699. (doi:10.1530/rep.0. 1260689)

Garrido-Gracia JC, Gordon A, Bellido C, Aguilar R, Barranco I, Millán Y, Martín de las Mulas J \& Sánchez-Criado JE 2007 The integrated action of oestrogen receptor isoforms and sites with progesterone receptor in the gonadotrope modulate $\mathrm{LH}$ secretion: evidence from tamoxifen-treated ovariectomized rats. Journal of Endocrinology 193 107-119. (doi:10. 1677/JOE-06-0214)

Gordon A, Garrido-Gracia JC, Aguilar R, Bellido C, Garcia Velasco JA, Millan Y, Tena-Sempere M, Martín de las Mulas J \& Sánchez-Criado JE 2008 The ovary-mediated FSH-attenuation of the $\mathrm{LH}$ surge in the rat involves a decreased gonadotroph progesterone receptor PR action but not PR expression. Journal of Endocrinology 196 585-594. (doi:10.1677/ JOE-07-0223)

Gordon A, Garrido-Gracia JC, Aguilar R \& Sánchez-Criado JE 2009a Ovarian stimulation with $\mathrm{FSH}$ in the rat reduces proestrous $\mathrm{GnRH}$ dependent $\mathrm{LH}$ secretion through a dual mechanism: inhibition of $\mathrm{LH}$ synthesis and release. Neuroscience Letters 460 219-222. (doi:10.1016/ j.neulet.2009.05.055)

Gordon A, Garrido-Gracia JC, Aguilar R, Guil-Luna S, Millán Y, de Las Mulas JM \& Sánchez-Criado JE 2009b Ovarian stimulation with FSH reduces phosphorylation of gonadotrope progesterone receptor and $\mathrm{LH}$ secretion in the rat. Reproduction 137 151-159. (doi:10.1530/REP-080318)

Guerra-Araiza C, Reyna-Neyra A, Salazar AM, Cerbón MA, Morimoto S \& Camacho-Arroyo I 2001 Progesterone receptor isoforms expression in the prepuberal and adult male rat brain. Brain research Bulletin 54 13-17. (doi:10.1016/S0361-9230(00)00410-X)

Guerra-Araiza C, Villamar-Cruz O, González-Arenas A, Chavira R \& Camacho-Arroyo I 2003 Changes in progesterone receptor isoforms 
content in the rat brain during the oestrous cycle and after oestradiol and progesterone treatments. Journal of Neuroendocrinology 15 984-990. (doi:10.1046/j.1365-2826.2003.01088.x)

Herbison AE 2007 Estrogen positive feedback to gonadotropin-releasing hormone $(\mathrm{GnRH})$ neurons in the rodent: the case for the rostral periventricular area of the third ventricle (RP3V). Brain Research Reviews 57 277-287. (doi:10.1016/j.brainresrev.2007.05.006)

Kastner P, Krust A, Turcotte B, Stropp U, Tora L, Gronemeyer H \& Chambon P 1990 Two distinct estrogen-regulated promoters generate transcripts encoding the two functionally different human progesterone receptor forms A and B. EMBO Journal 9 1603-1614.

Khan JA, Amazit L, Bellance C, Guiochon-Mantel A, Lombès M \& Loosfelt H 2011 p38 and p42/44 MAPKs differentially regulate progesterone receptor $\mathrm{A}$ and $\mathrm{B}$ isoform stabilization. Molecular Endocrinology 25 1710-1724. (doi:10.1210/me.2011-1042)

Knutson TP, Daniel AR, Fan D, Silverstein KA, Covington KR, Fuqua SA \& Lange CA 2012 Phosphorylated and sumoylation-deficient progesterone receptors drive proliferative gene signatures during breast cancer progression. Breast Cancer Research 14 R95. (doi:10.1186/ bcr3211)

Lange CA 2008 Integration of progesterone receptor action with rapid signaling events in breast cancer models. Journal of Steroid Biochemistry and Molecular Biology 108 203-212. (doi:10.1016/j.jsbmb.2007.09.019)

Lange CA, Shen T \& Horwitz KB 2000 Phosphorylation of human progesterone receptors at serine-294 by mitogen-activated protein kinase signals their degradation by the 26S proteasome. PNAS 97 1032-1037. (doi:10.1073/pnas.97.3.1032)

Levine JE, Chappell PE, Schneider JS, Sleiter NC \& Szabo M 2001 Progesterone receptors as neuroendocrine integrators. Frontiers in Neuroendocrinology 22 69-106. (doi:10.1006/frne.2001.0210)

Messinis IE 2006 Ovarian feedback, mechanism of action and possible clinical implications. Human Reproduction Update 12 557-571. (doi:10.1093/humupd/dml020)

Moore NL, Narayanan R \& Weigel NL 2007 Cyclin dependent kinase 2 and the regulation of human progesterone receptor activity. Steroids $\mathbf{7 2}$ 202-209. (doi:10.1016/j.steroids.2006.11.025)

Mote PA, Bartow S, Tran N \& Clarke CL 2002 Loss of co-ordinate expression of progesterone receptors $\mathrm{A}$ and $\mathrm{B}$ is an early event in breast carcinogenesis. Breast Cancer Research and Treatment 72 163-172. (doi:10.1023/A:1014820500738)

Pierson-Mullany LK \& Lange CA 2004 Phosphorylation of progesterone receptor serine 400 mediates ligand-independent transcriptional activity in response to activation of cyclin-dependent protein kinase 2. Molecular and Cellular Biology 24 10542-10557. (doi:10.1128/MCB.24.24. 10542-10557.2004)
Sánchez-Criado JE, Bellido C, Galiot F, López FJ \& Gaytán F 1990 A possible dual mechanism of the anovulatory action of antiprogesterone RU486 in the rat. Biology of Reproduction 42 877-886.

Sánchez-Criado JE, Hernandez G, Bellido C, Gonzalez D, Tébar M, DiazCruz MA \& Alonso R 1994 Periovulatory LHRH, LH and FSH secretion in cyclic rats treated with RU486: effects of exogenous $\mathrm{LHRH}$ and $\mathrm{LHRH}$ antagonist on $\mathrm{LH}$ and FSH secretion at early oestrus. Journal of Endocrinology 141 7-14.

Sánchez-Criado JE, de Las Mulas JM, Bellido C, Aguilar R \& GarridoGracia JC 2005 Gonadotrope oestrogen receptor-alpha and -beta and progesterone receptor immunoreactivity after ovariectomy and exposure to oestradiol benzoate, tamoxifen or raloxifene in the rat: correlation with LH secretion. Journal of Endocrinology 184 59-68.

Shyamala G, Yang X, Silberstein G, Barcellos-Hoff MH \& Dale E 1998 Transgenic mice carrying an imbalance in the native ratio of $A$ to $B$ forms of progesterone receptor exhibit developmental abnormalities in mammary glands. PNAS 95 696-701. (doi:10.1073/pnas.95.2.696)

Takimoto GS \& Horwitz KB 1993 Progesterone receptor phosphorylation: complexities in defining a functional role. Trends in Endocrinology and Metabolism 4 1-7. (doi:10.1016/1043-2760(93)90056-K)

Tébar M, Ruiz A \& Sánchez-Criado JE 1998 Involvement of estrogen and follicle-stimulating hormone on basal and luteinizing hormone (LH)releasing hormone-stimulated $\mathrm{LH}$ secretion in RU-486-induced 3-day estrous cycle in the rat. Biology of Reproduction 58 615-619.

Turgeon JL \& Waring DW 1994 Activation of the progesterone receptor by the gonadotropin-releasing hormone self-priming signaling pathway. Molecular Endocrinology 8 860-869.

Turgeon JL \& Waring DW 2000 Progesterone regulation of the progesterone receptor in rat gonadotrope. Endocrinology 141 3422-3429.

Turgeon JL \& Waring DW 2001 Luteinizing hormone secretion from wildtype and progesterone receptor knockout mouse anterior pituitary cells. Endocrinology 142 3108-3115.

Turgeon JL, Van Patten SM, Shyamala G \& Waring DW 1999 Steroid regulation of progesterone receptor expression in cultured rat gonadotropes. Endocrinology $1402318-2325$.

Waring DW \& Turgeon JL 1992 A pathway for luteinizing hormone releasing-hormone self-potentiation: cross-talk with the progesterone receptor. Endocrinology 130 3275-3282.

Received 10 November 2014

First decision 19 December 2014

Revised manuscript received 9 March 2015

Accepted 23 March 2015 